\title{
DEM-CFD modeling and simulations of hydrodynamic characteristics and flow resistance coefficient in fixed-bed reactors
}

\author{
Yaping $\mathrm{Li}^{1}$, Le Xie ${ }^{1}$, Yonghua Zhou ${ }^{1}$, Chongwen Jiang ${ }^{1}$, and Hong Zhong ${ }^{1}$ \\ ${ }^{1}$ Central South University
}

January 6, 2021

\begin{abstract}
The ability to predict void fraction, pressure drop, and flow resistance coefficient in fixed-bed reactors is significant to their optimal design. In this study, the discrete element method (DEM) is combined with computational fluid dynamics (CFD) to simulate the hydrodynamic characteristics of fixed-beds. A realistic random packing structure for fixed-beds with spherical particles was generated via the DEM method and then meshed using Ansys ICEM software for the CFD simulation. A grid independency study was performed to select appropriate grid model parameters. A large set of numerical experiments was conducted to investigate the hydrodynamic characteristics with respect to different inlet velocities and particle sizes, and the simulated pressure drop data were used to calculate the flow resistance coefficient. The output flow resistance coefficients agreed well with those calculated by the classical models in laminar and turbulent flow regimes, thereby indicating the accuracy and advantage of the proposed DEM-CFD approach.
\end{abstract}

\section{Hosted file}

DEM-CFD modeling and simulations of hydrodynamic characteristics and drag coefficient in fixed bed reac available at https://authorea.com/users/387630/articles/502622-dem-cfd-modeling-andsimulations-of-hydrodynamic-characteristics-and-flow-resistance-coefficient-in-fixedbed-reactors 